\title{
Deepwater Horizon Oil Spill Impacts on Salt Marsh Fiddler Crabs (Uca spp.)
}

\author{
Scott Zengel ${ }^{1} \cdot$ Steven C. Pennings ${ }^{2} \cdot$ Brian Silliman $^{3} \cdot$ Clay Montague $^{4}$. \\ Jennifer Weaver $^{5} \cdot$ Donald R. Deis $^{6} \cdot$ Michelle O. Krasnec $^{7} \cdot$ Nicolle Rutherford ${ }^{8}$ • \\ Zachary Nixon ${ }^{5}$
}

Received: 9 November 2015 / Revised: 8 January 2016 / Accepted: 26 January 2016 / Published online: 3 February 2016

(C) The Author(s) 2016. This article is published with open access at Springerlink.com

\begin{abstract}
The Deepwater Horizon oil spill was the largest marine oil spill in US waters to date and one of the largest worldwide. Impacts of this spill on salt marsh vegetation have been well documented, although impacts on marsh macroinvertebrates have received less attention. To examine impacts of the oil spill on an important marsh invertebrate and ecosystem engineer, we conducted a meta-analysis on fiddler crabs (Uca spp.) using published sources and newly available Natural Resources Damage Assessment (NRDA) and Gulf of Mexico Research Initiative (GoMRI) data. Fiddler crabs influence marsh ecosystem structure and function through their burrowing and feeding activities and are key prey for a number of marsh and estuarine predators. We tested the hypothesis that the spill affected fiddler crab burrow density (crab abundance), burrow diameter (crab size), and crab
\end{abstract}

Communicated by Kenneth Dunton

Scott Zengel

szengel@researchplanning.com

1 Research Planning, Inc. (RPI), Tallahassee, FL 32303, USA

2 Department of Biology and Biochemistry, University of Houston, Houston, TX 77204, USA

3 Duke University Marine Laboratory, Beaufort, NC 28516, USA

4 Department of Environmental Engineering Sciences, University of Florida, Gainesville, FL 32611, USA

5 Research Planning, Inc. (RPI), Columbia, SC 29201, USA

6 Atkins, Jacksonville, FL 32256, USA

7 Abt Associates, Boulder, CO 80302, USA

8 Emergency Response Division, Office of Response and Restoration, National Ocean Service, National Oceanographic and Atmospheric Administration (NOAA), Seattle, WA 98115, USA species composition. Averaged across multiple studies, sites, and years, our synthesis revealed a negative effect of oiling on all three metrics. Burrow densities were reduced by $39 \%$ in oiled sites, with impacts and incomplete recovery observed over 2010-2014. Burrow diameters were reduced from 2010 to 2011, but appeared to have recovered by 2012. Fiddler crab species composition was altered through at least 2013 and only returned to reference conditions where marsh vegetation recovered, via restoration planting in one case. Given the spatial and temporal extent of data analyzed, this synthesis provides compelling evidence that the Deepwater Horizon spill suppressed populations of fiddler crabs in oiled marshes, likely affecting other ecosystem attributes, including marsh productivity, marsh soil characteristics, and associated predators.

Keywords Deepwater Horizon · Oil spill · Salt marsh · Fiddler crabs $\cdot$ Uca longisignalis $\cdot$ Uca spinicarpa

\section{Introduction}

The Deepwater Horizon oil spill was the largest marine oil spill in US waters to date and one of the largest worldwide: over 3 million barrels of crude oil were released into the Gulf of Mexico (U.S. District Court 2015), and over $1700 \mathrm{~km}$ of coastal shorelines were oiled (Michel et al. 2013). Impacts of this oil spill on salt marsh vegetation have been well documented (Lin and Mendelssohn 2012; Silliman et al. 2012; Zengel et al. 2015a). In comparison, impacts of this spill on salt marsh macroinvertebrates have received little direct attention (although see McCall and Pennings 2012, focused mainly on insects; and Zengel et al. 2015b addressing marsh periwinkles). As part of the Natural Resources Damage Assessment (NRDA) process, we addressed the impact of the Deepwater Horizon oil spill on fiddler crabs (Uca spp.), 
the dominant crab species in salt marshes in the Gulf region and an important ecosystem engineer and prey species.

Fiddler crabs are prolific burrowers in marsh substrates and process large amounts of sediments and organic material during feeding. Fiddler crabs can have important influences on marsh vegetation, marsh soils, benthic algae, detritus and organic material, nutrient cycling, microbial communities, and meiofauna through their burrowing and feeding activities (Teal 1962; Montague 1980, 1982; Katz 1980; Hoffman et al. 1984; Bertness 1985; DePatra and Levin 1989; Taylor and Allanson 1993; Gribsholt et al. 2003; Holdredge et al. 2010; Thomas and Blum 2010; Smith and Tyrrell 2012; Gittman and Keller 2013). For example, fiddler crab burrowing can increase the growth and biomass of Spartina alterniflora, the foundation plant species in salt marshes, through the combined effects of added nutrients, lower salinity, greater oxygen, lower sulfide, and greater water movement through marsh soils (Montague 1982). Fiddler crabs are also important prey for many species of commercial, recreational, and conservation interest, including blue crab (Callinectes sapidus), red drum (Sciaenops ocellatus), diamondback terrapin (Malaclemys terrapin), clapper rail (Rallus longirostris), wading birds, migratory shorebirds, and raccoon (Procyon lotor) (Teal 1962; Harmon and Stains 1979; Montague 1980; Heard 1982; Grimes et al. 1989; Tucker et al. 1995). Accordingly, reductions in fiddler crabs and fiddler crab burrows could have profound effects on salt marsh structure and function, as well as a variety of marsh and estuarine predators.

In general, previous studies have reported negative effects of prior oil spills on fiddler crabs, including increased mortality, reduced burrow density, impaired locomotion and behavior, abnormal burrow construction, changes in sex ratio, and reduced juvenile settlement (Rützler and Sterrer 1970; Krebs and Burns 1977; Burns and Teal 1979; Teal and Howarth 1984; Burger et al. 1991, 1992; Teal et al. 1992; Culbertson et al. 2007; Melville et al. 2009). However, many of these studies were associated with a single prior oil spill in New England, USA, affecting a relatively small area of marsh compared to the Deepwater Horizon spill. In addition, these prior spills and studies differed from the Deepwater Horizon spill in several other important ways: (1) all were located outside the Gulf of Mexico region; (2) all involved different species of fiddler crabs; (3) all were shallow, nearshore spills that rapidly affected shorelines, whereas oil from the offshore Deepwater Horizon release weathered at sea for 2 weeks or more before reaching shore; and (4) all were spills of refined products, especially No. 2 fuel oil, which is generally more toxic than most crude oils (Michel and Rutherford 2014). These differences could result in varying ecological responses to oiling.

Four published studies have touched on the effects of the Deepwater Horizon oil spill on fiddler crabs (McCall and Pennings 2012; Silliman et al. 2012; Zengel et al. 2014, 2015a). However, these studies primarily focused on other topics and were limited in timing, duration, number of sites studied, or specific locations and conditions examined relative to fiddler crabs. The effects of the oil spill on fiddler crabs were not always clear or consistent within or among these studies. As described for salt marsh fishes, it can be difficult to discern population and community effects from even large oil spills, hence the need for synthesis across multiple studies (Fodrie et al. 2014). Here, we synthesize results of these four studies along with previously unpublished data from the Natural Resources Damage Assessment (NRDA) and an ongoing Gulf of Mexico Research Initiative (GoMRI) study (Deis et al. 2015) in a meta-analysis to provide a comprehensive assessment of how the Deepwater Horizon oil spill directly affected fiddler crabs. We tested the hypothesis that the oil spill reduced fiddler crab burrow density (crab abundance), reduced burrow diameter (crab size), and altered fiddler crab species composition in salt marshes that were heavily to moderately oiled.

\section{Methods}

Studies We synthesized comparable results of all published studies and additional unpublished data including large NRDA and GoMRI data sets (Table 1). Detailed methods are included in each of the published studies and are available for the NRDA (Michel et al. 2012; Zengel et al. 2015b) and GoMRI (Deis et al. 2015) sources. Study sites were widely distributed throughout the northern Gulf of Mexico (LA, MS, $\mathrm{AL})$ with numerous sites concentrated in southeastern Louisiana (Barataria and Terrebonne Bays), where salt marsh oiling was most widespread and severe (Fig. 1).

Sites were categorized as oiled or reference sites by the primary investigators using somewhat different criteria, but all the studies described visibly oiled sites with heavy to moderate oiling. The vast majority of the oiled sites corresponded to the NRDA "heavier persistent oiling" category, defined as marsh shorelines with heavy to moderate oiling that persisted on the shoreline for 3 months or longer. All studies reported that their reference sites had no visible oiling at the time data were collected.

Some of the oiled sites had shoreline cleanup treatments applied as part of the Deepwater Horizon emergency response, involving manual and mechanical treatments including removal of oiled wrack, raking and cutting of oiled marsh vegetation (mainly oiled and dead vegetation), and raking and scraping of oil deposits from the marsh substrate (Zengel et al. $2015 \mathrm{a}, \mathrm{b})$. Because we were interested in examining the overall impacts of the oil spill, including effects of oiling and any associated shoreline treatment, and because some sources did not describe whether sites were treated or not, we pooled all oiled sites into a single category regardless of whether or not they had been treated. Though some initial positive effects of shoreline treatment on fiddler crab burrow density were 
Table 1 Summary of fiddler crab data sources used in the meta-analysis

\begin{tabular}{lllllll}
\hline Source & Years & Zones & Burrow density & Burrow diameter & Species composition & References/notes \\
\hline Silliman & $2010-2012$ & $1-2$ & $\mathrm{X}$ & & & Silliman et al. 2012, including unpublished data \\
Pennings & $2010-2011$ & 3 & $\mathrm{X}$ & $\mathrm{X}^{\mathrm{a}}$ & & McCall and Pennings 2012, including unpublished data \\
NRDA & 2011 & $1-3$ & $\mathrm{X}$ & $\mathrm{X}$ & $\mathrm{X}$ & Previously unpublished NRDA data \\
Zengel & $2011-2014$ & 1 & $\mathrm{X}$ & $\mathrm{X}^{\mathrm{b}}$ & $\mathrm{X}^{\mathrm{c}}$ & Zengel et al. 2014, 2015a, including unpublished data \\
Deis & $2012-2014$ & 1 & $\mathrm{X}$ & $\mathrm{X}$ & & Deis et al. 2015, including unpublished data \\
\hline
\end{tabular}

${ }^{\text {a } 2010 \text { only }}$

b 2012-2014 only

c 2012-2013 only

observed in heavily oiled sites during this spill compared to oiled and untreated sites, such effects were not persistent over time and did not extend to other fiddler crab metrics examined (Zengel et al. 2014, 2015a).

Nearly all sites, reference and oiled, were located in mainland herbaceous salt marsh with muddy organic soils. Three sites in one study (two reference and one oiled, McCall and Pennings 2012) and one reference site in another (Silliman et al. 2012) were located in back barrier island salt marsh and may have had somewhat sandier soils. The salt marsh vegetation at all sites was naturally dominated by Spartina alterniflora and in some cases Juncus roemerianus, the typical salt marsh species in the region. Reference versus oiled sites were compared within individual studies across metrics including soils, salinity, vegetation types, etc. and were found to be generally similar in terms of habitat for fiddler crabs, other than oiling conditions and subsequent impacts to the marsh habitat. Based on geographic location, marsh type, soils, and salinity, most sites would be expected to have been dominated by Uca longisignalis (Mouton and Felder 1995, 1996). The few back barrier sites may have been dominated or co-dominated by $U$. panacea if on sandier soils.

Some studies collected data in different seasons of the year, which potentially could confound oil-spill effects with natural variation across seasons (Mouton and Felder 1996). Because most data were collected in the summer and fall (June through early November), which are the warmer months during which crabs would be most active, we limited our analyses to data collected during this period to standardize for season.

Marsh Zones Oil was deposited most heavily along the seaward edge of marshes, with gross visible oiling typically limited to $\sim 10-20 \mathrm{~m}$ from the shoreline, though oil extended further into the marsh in some areas (Lin and Mendelssohn 2012; Silliman et al. 2012; Kokaly et al. 2013; Michel et al. 2013; Zengel et al. 2015a, b). Fiddler crabs naturally vary in distribution and abundance between the marsh edge and interior (Peterson and Turner 1994; Mouton and Felder 1996), with burrow densities typically being lowest at the marsh edge and increasing inland to $\sim-15 \mathrm{~m}$ from the shoreline (Mouton and Felder 1996). We therefore divided the data into three "marsh zones". Zone 1 was defined as the seaward marsh edge, where oiling was typically heaviest ( $\sim-6 \mathrm{~m}$ from the shoreline, depending on oiling width across shore). Zone 2 was defined as the marsh interior within the main oiling band ( $\sim 6-15 \mathrm{~m}$ from the shoreline, depending on oiling width). Zone 3 was defined as the marsh interior a few meters landward (inland) of the main oiling band, with light to no visible

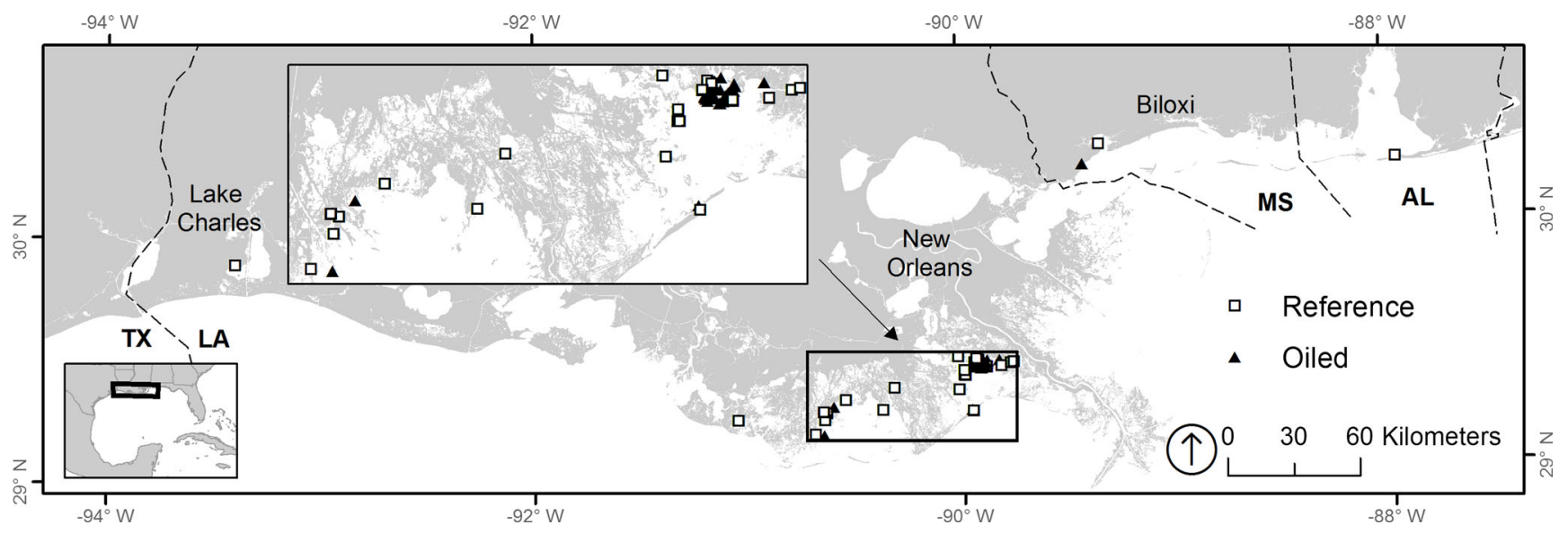

Fig. 1 Study area map with reference and oiled sampling sites 
oiling and intact marsh vegetation. Designations for marsh edge versus marsh interior were similar to Peterson and Turner (1994). Data were assigned to the most appropriate zone designations based on these criteria. Due to shoreline erosion, sampling position relative to distance from the shoreline was not static over time; however, even in later sampling years, Zone 1 sampling sites were still located within the shoreline widths most affected by oiling and most similar to earlier Zone 1 locations (and these sites had not yet eroded beyond the areas with heaviest oiling). In some cases, these sites in later years may have been bordering on locations that would have originally been considered Zone 2 . In all cases, zones at the reference sites were located at distances comparable to those of the oiled sites.

Burrow Density All the studies estimated crab abundance based on counts of crab burrows (\# burrows $\mathrm{m}^{-2}$ ). Direct counting of crabs requires excavating sediment to the maximum depth of burrows, which is both time consuming and damaging to the habitat (Mouton and Felder 1996) and could result in worsening subsurface soil contamination in oiled sites by mixing oil into the soils. There is not always a $1: 1$ relationship between fiddler crab abundance and burrow density; however, for the species studied, crab density has been estimated to be $75-100 \%$ of burrow density in Louisiana (Mouton and Felder 1996). Fiddler crabs were the most abundant burrowing crab species observed at these sites, so burrow counts were unlikely to be highly influenced by the abundance of other burrowing crab species. We were able to compile burrow count data for 16 study-zone-by-year combinations. We analyzed these data in two ways. First, we compared burrow density between oiled and reference sites using a $t$ test for each study-zone-by-year combination. Data were $\log (x+0.1)$ transformed prior to analysis to improve normality, and Welch's statistic was used where variances were unequal. We also analyzed the untransformed data using a nonparametric Mann-Whitney U (MWU) test. Second, we estimated the effect of the oil spill using log response ratios, $\ln$ (burrow density at oiled sites/burrow density at reference sites) for each study-zone-by-year combination (after Hedges et al. 1999). The log response ratio is zero if oiled and reference sites are identical, and negative if burrow densities are lower at oiled sites. We compared the log response ratio to zero across all study-zone-by-year combinations using a one-sample $t$ test and a non-parametric Wilcoxon signed-rank test. Back-calculating from the log response ratio, we determined the mean response ratio and asymmetrical $95 \%$ confidence intervals calculated from the $t$ test and converted these to an estimate of mean proportional reduction in burrow density with oiling (with lower $95 \%$ confidence boundary). For all analyses, we defined statistical significance as $p \leq 0.10$ based on guidance from Mapstone (1995) designed to better balance type I and type
II errors during environmental impact studies. All statistical tests across the study were one-tailed.

Burrow Diameter A subset of studies estimated relative crab size based on burrow diameter (millimeter) (Table 1). This is a common field method, and a strong relationship exists between crab carapace width and burrow diameter (Mouton and Felder 1996). We were able to compile burrow diameter data for 10 study-zone-by-year combinations. As for burrow density, we first compared burrow diameter (without transformation) between oiled and reference sites using a $t$ test and MWU test for each study-zone-by-year combination and second estimated the effect of oiling on burrow diameter across all study-zone-by-year combinations by comparing the log response ratios of burrow diameter to zero using a one sample $t$ test and Wilcoxon signed-rank test.

Species Composition A subset of studies captured fiddler crabs $(n=1384)$ on the marsh surface and from burrow entrances to estimate relative species composition (Table 1). Without excavating the marsh to collect every single individual, this is a practical, less destructive way to compare the relative abundances of different species. However, different species may vary in surface activity so this method can only provide a rough index of species composition. We compiled species composition data for five study-zone-by-year combinations. Most crabs were identified as $U$. longisignalis or $U$. spinicarpa; a few were identified as $U$. rapax or $U$. panacea; no $U$. minax was observed; and some fiddler crabs were too small to be reliably identified to species. Therefore, we focused our analysis on the relative abundances of $U$. longisignalis and $U$. spinicarpa. Species composition was expressed as the proportion of $U$. longisignalis to ( $U$. longisignalis $+U$. spinicarpa) for analysis. $U$. longisignalis is the typical dominant in densely vegetated salt marsh in the region; U. spinicarpa is the main secondary species in salt marsh and dominates in sparsely vegetated areas with clay soils, such as along dredged canal banks (Mouton and Felder 1995, 1996). As was done for burrow density and diameter, we first compared species composition between oiled and reference sites using a $t$ test and MWU test for each study-zone-by-year combination. Data were arcsine square root transformed for the $t$ tests to improve normality. Second, we estimated the effect of oiling on species composition across all study-zone-by-year combinations by comparing the log response ratios to zero using a one sample $t$ test and Wilcoxon signed-rank test.

\section{Results}

Burrow Density Crab burrow densities tended to be lower at oiled sites than at reference sites for nearly all combinations of study-zone-by-year (Table 2, Fig. 2). The two exceptions were 
Table 2 Fiddler crab burrow density summary table

\begin{tabular}{|c|c|c|c|c|c|c|c|c|c|c|c|}
\hline \multicolumn{3}{|c|}{ Data source } & \multicolumn{2}{|c|}{ Number of observations } & \multicolumn{2}{|c|}{ Mean \pm SE (\# burrows $\mathrm{m}^{-2}$ ) } & \multicolumn{3}{|c|}{ Oiled : reference response ratios } & \multicolumn{2}{|c|}{ Significance tests ( $p$ values) } \\
\hline Year & Study & Zone & Ref. & Oiled & Reference & Oiled & $\mathrm{RR}$ & $\ln \mathrm{RR}$ & reduction & $t$ test & MWU test \\
\hline 2010 & Silliman & 1 & 3 & 3 & $9.1 \pm 4.6$ & $4.7 \pm 1.7$ & 0.51 & -0.66 & 0.49 & 0.60 & 0.35 \\
\hline 2010 & Silliman & 2 & 3 & 3 & $35.7 \pm 1.9$ & $28.5 \pm 9.0$ & 0.80 & -0.23 & 0.20 & 0.20 & 0.35 \\
\hline 2010 & Pennings & 3 & 5 & 5 & $25.7 \pm 5.9$ & $8.4 \pm 3.7$ & 0.32 & -1.12 & 0.68 & 0.02 & 0.03 \\
\hline 2011 & NRDA & 1 & 9 & 23 & $24.9 \pm 9.1$ & $20.6 \pm 5.1$ & 0.83 & -0.19 & 0.17 & 0.04 & 0.16 \\
\hline 2011 & Zengel & 1 & 5 & 19 & $17.3 \pm 1.2$ & $11.1 \pm 2.0$ & 0.64 & -0.45 & 0.36 & 0.01 & 0.04 \\
\hline 2011 & NRDA & 2 & 11 & 24 & $59.5 \pm 13.0$ & $49.2 \pm 6.0$ & 0.83 & -0.19 & 0.17 & 0.35 & 0.29 \\
\hline 2011 & NRDA & 3 & 11 & 24 & $53.5 \pm 12.1$ & $65.9 \pm 10.9$ & 1.23 & 0.21 & -0.23 & 0.61 & 0.67 \\
\hline 2011 & Pennings & 3 & 6 & 5 & $30.2 \pm 6.3$ & $24.4 \pm 9.2$ & 0.81 & -0.21 & 0.19 & 0.21 & 0.27 \\
\hline 2012 & Silliman & 1 & 12 & 8 & $18.3 \pm 3.0$ & $12.0 \pm 3.2$ & 0.65 & -0.42 & 0.35 & 0.25 & 0.08 \\
\hline 2012 & Zengel & 1 & 5 & 19 & $15.7 \pm 2.8$ & $11.4 \pm 1.6$ & 0.72 & -0.32 & 0.28 & 0.04 & 0.13 \\
\hline 2012 & Deis & 1 & 7 & 14 & $20.6 \pm 6.4$ & $8.9 \pm 3.4$ & 0.43 & -0.84 & 0.57 & 0.04 & 0.04 \\
\hline 2012 & Silliman & 2 & 6 & 4 & $16.0 \pm 2.1$ & $10.0 \pm 4.2$ & 0.62 & -0.47 & 0.38 & 0.16 & 0.11 \\
\hline 2013 & Zengel & 1 & 5 & 10 & $11.2 \pm 2.5$ & $2.5 \pm 1.1$ & 0.22 & -1.50 & 0.78 & $<0.01$ & $<0.01$ \\
\hline 2013 & Deis & 1 & 7 & 14 & $17.7 \pm 5.4$ & $12.9 \pm 7.0$ & 0.73 & -0.32 & 0.27 & $<0.01$ & 0.03 \\
\hline 2014 & Zengel & 1 & 5 & 10 & $19.2 \pm 6.8$ & $5.4 \pm 2.2$ & 0.28 & -1.27 & 0.72 & 0.01 & 0.02 \\
\hline 2014 & Deis & 1 & 7 & 14 & $10.3 \pm 4.8$ & $11.7 \pm 3.9$ & 1.14 & 0.13 & -0.14 & 0.45 & 0.53 \\
\hline
\end{tabular}

Data include response ratios (RR) (burrow densities for oiled sites/burrow densities for reference sites), proportional reduction with oiling (reduction), and significance tests for each combination of study-zone-by-year. Log response ratios (ln RR) less than zero indicate lower burrow densities for oiled versus reference sites. Raw density data were $\log (\mathrm{x}+0.1)$ transformed for $t$ tests, non-parametric Mann-Whitney $\mathrm{U}(\mathrm{MWU})$ tests also included

Zone 3 in 2011 and one of two studies in Zone 1 in 2014. Half of the study-zone-by-year combinations were statistically significant, spanning multiple studies (Table 2). Though no corrections of $p$ values were applied to address multiple tests, less than two significant results would have been expected by chance, but 7-8 were significant (whether relying on $t$ tests or MWU tests). As a whole, the log response ratio values were significantly different from zero, indicating that the oil spill

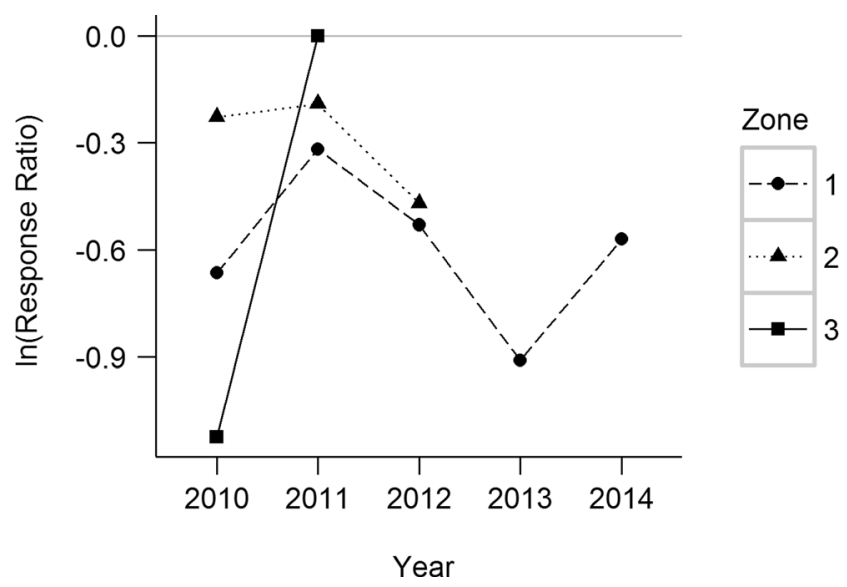

Fig. 2 Log response ratios (oiled : reference) for fiddler crab burrow density by zone and year. Where more than one study contributed data for any zone-by-year combination, average values were plotted. Values less than zero indicate lower burrow densities for oiled versus reference sites. Log response ratios were significantly lower than zero for the combined analysis across all study-zone-by-year observations ( $t$ test, $p<0.01$; Wilcoxon signed-ranked test, $p<0.01$ ) reduced burrow densities in the oiled sites relative to reference conditions (Fig. 2). Examining the data by zone and over time, most Zone 1 differences were statistically significant, and recovery of oiled sites to reference levels was not exhibited overall (Fig. 2). Zone 2 differences were not significant but the trend in the data was similar to that of Zone 1 in oiling effects and lack of recovery (Fig. 2). Zone 3 differences were statistically significant in 2010 , shortly after heavy oiling first came ashore, but fiddler crab burrow densities at oiled sites recovered to reference levels by 2011. On average, burrow densities across all study-zone-by-year combinations were reduced by $39 \%$ in the oiled sites $(95 \%$ lower confidence bound $=25 \%$ reduction).

Burrow Diameter Burrow diameters were 21 and $44 \%$ percent smaller at oiled compared to reference sites for the two statistically significant comparisons (Zone 3 in 2010 and Zone 1 in 2011) (Table 3, Fig. 3). In this case, only one significant difference would have been expected by chance. As a group, log response ratio values were not different from zero. Examining the data by zone and over time, burrow diameters appeared to be initially reduced in the oiled sites but recovered during the study period (by 2012 for Zone 1, by 2011 for Zone 3, and perhaps also by 2011 in Zone 2).

Species Composition The most common fiddler crab species at the study sites was $U$. longisignalis; however, it tended to be 
Table 3 Fiddler crab burrow diameter summary table

\begin{tabular}{|c|c|c|c|c|c|c|c|c|c|c|c|}
\hline \multicolumn{3}{|c|}{ Data source } & \multicolumn{2}{|c|}{ Number of observations } & \multicolumn{2}{|c|}{ Mean \pm SE (diameter, mm) } & \multicolumn{3}{|c|}{ Oiled : reference response ratios } & \multicolumn{2}{|c|}{ Significance tests ( $p$-values) } \\
\hline Year & Study & Zone & Ref. & Oiled & Reference & Oiled & $\mathrm{RR}$ & $\ln \mathrm{RR}$ & reduction & $t$-test & MWU \\
\hline 2010 & Pennings & 3 & 5 & 5 & $14.7 \pm 1.3$ & $8.2 \pm 1.0$ & 0.56 & -0.58 & 0.44 & $<0.01$ & $<0.01$ \\
\hline 2011 & NRDA & 1 & 9 & 19 & $7.7 \pm 0.6$ & $6.1 \pm 0.5$ & 0.79 & -0.24 & 0.21 & 0.02 & 0.03 \\
\hline 2011 & NRDA & 2 & 11 & 24 & $7.5 \pm 0.5$ & $7.0 \pm 0.3$ & 0.94 & -0.06 & 0.06 & 0.22 & 0.31 \\
\hline 2011 & NRDA & 3 & 11 & 23 & $6.6 \pm 0.6$ & $7.5 \pm 0.4$ & 1.14 & 0.13 & -0.14 & 0.89 & 0.84 \\
\hline 2012 & Zengel & 1 & 5 & 19 & $9.4 \pm 1.4$ & $9.9 \pm 0.6$ & 1.05 & 0.05 & -0.05 & 0.61 & 0.61 \\
\hline 2012 & Deis & 1 & 6 & 5 & $9.4 \pm 1.4$ & $9.7 \pm 1.9$ & 1.02 & 0.02 & -0.02 & 0.54 & 0.53 \\
\hline 2013 & Zengel & 1 & 5 & 7 & $10.1 \pm 2.2$ & $15.3 \pm 1.7$ & 1.52 & 0.42 & -0.52 & 0.95 & 0.98 \\
\hline 2013 & Deis & 1 & 4 & 5 & $16.9 \pm 0.9$ & $17.1 \pm 3.9$ & 1.01 & 0.01 & -0.01 & 0.51 & 0.10 \\
\hline 2014 & Zengel & 1 & 5 & 7 & $11.7 \pm 1.8$ & $12.6 \pm 1.9$ & 1.08 & 0.07 & -0.08 & 0.63 & 0.50 \\
\hline 2014 & Deis & 1 & 5 & 10 & $7.0 \pm 1.3$ & $9.6 \pm 1.6$ & 1.36 & 0.31 & -0.36 & 0.89 & 0.80 \\
\hline
\end{tabular}

Data include response ratios (RR) (burrow diameters for oiled sites/burrow diameters for reference sites), proportional reduction with oiling (reduction), and significance tests for each combination of study-zone-by-year. Number of observations refers to study sites compared. Log response ratios (ln RR) less than zero indicate smaller burrow diameters for oiled versus reference sites. Raw diameter data were used for $t$ tests, non-parametric Mann-Whitney $\mathrm{U}$ (MWU) tests also included

proportionately less abundant in the oiled versus reference sites for all combinations of study-zone-by-year (Table 4, Fig. 4). Three of the five study-zone-by-year combinations were statistically significant. Less than one significant difference would have been expected by chance. As a whole, the $\log$ response ratios were also significantly different from zero, indicating that oiling reduced the numerical dominance of $U$. longisignalis and increased the relative abundance of the only other common species, $U$. spinicarpa. Changes in species composition occurred in each zone, and recovery was not detected over time (though only one data source in Zone 1 had measurements in multiple years).

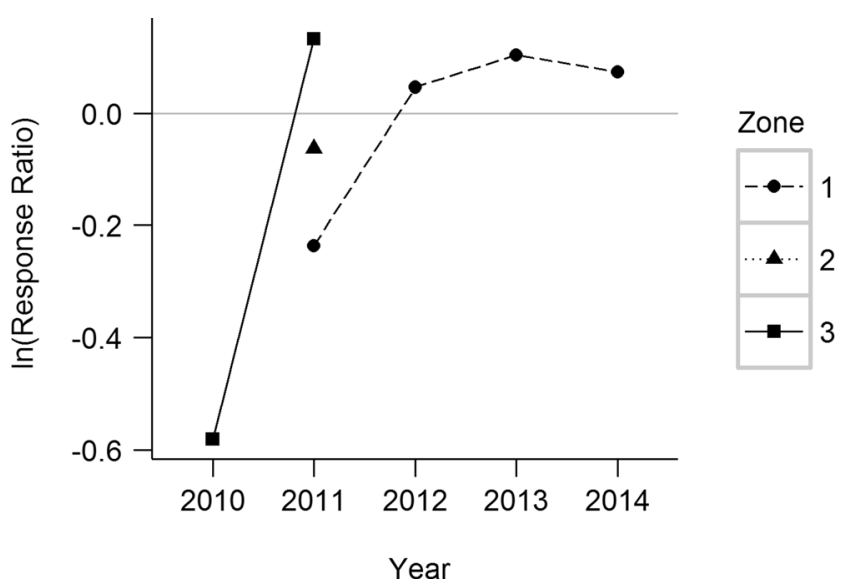

Fig. 3 Log response ratios (oiled : reference) for fiddler crab burrow diameter by zone and year. Values less than zero indicate smaller burrow diameters for oiled versus reference sites. Log response ratios were not significantly lower than zero for the combined analysis across all study-zone-by-year observations $(t$ test, $p=0.60$; Wilcoxon signed ranked test, $p=0.80$ )

\section{Discussion}

All three metrics indicated that the Deepwater Horizon oil spill negatively affected fiddler crab populations. Crabs at oiled sites were less abundant, were smaller for a period of time after the spill, and differed in species composition from crabs at reference sites. Below, we discuss the implications of each of these findings.

Burrow Density We found compelling evidence that the oil spill reduced fiddler crab burrow density from the oiled marsh edge into the marsh interior inland of the main oiling bands. Fewer crabs, less burrowing, and fewer crab burrows would be expected to affect marsh structure and function, including marsh plant productivity and soil characteristics. By 2014, more than 4 years after initial oiling, overall burrow density had not recovered to reference levels at the marsh edge. There appeared to be possible signs of recovery in one study in 2014, where oiling levels were moderate to heavy (Deis et al. 2015); however, the other study in 2014 displayed ongoing impacts, perhaps due to more persistent or heavier oiling (Zengel et al. 2015a; see also Fleeger et al. 2015). Longer-lasting impacts at the marsh edge are not surprising. Gross oiling levels were higher, and vegetation impacts were more pronounced at the seaward marsh edge (Lin and Mendelssohn 2012; Zengel et al. 2015b). Several authors have also documented accelerated marsh erosion due to vegetation impacts caused by the oil spill (Silliman et al. 2012; McClenachan et al. 2013; Zengel et al. 2015a). Accelerated marsh erosion may also result in direct loss of fiddler crabs and their habitat. However, such an effect was not investigated in our study, and therefore, our findings may underestimate total losses of fiddler crabs. 
Table 4 Fiddler crab species composition summary table

\begin{tabular}{|c|c|c|c|c|c|c|c|c|c|c|c|}
\hline \multicolumn{3}{|c|}{ Data source } & \multicolumn{2}{|c|}{ Number of observations } & \multicolumn{2}{|c|}{ Mean $\pm \mathrm{SE}$ (prpt. $U$. longisignalis) } & \multicolumn{3}{|c|}{ Oiled : reference response ratios } & \multicolumn{2}{|c|}{ Significance test ( $p$-values) } \\
\hline Year & Study & Zone & Ref. & Oiled & Reference & Oiled & $\mathrm{RR}$ & $\ln \mathrm{RR}$ & reduction & $t$-test & MWU \\
\hline 2011 & NRDA & 1 & 7 & 18 & $0.47 \pm 0.18$ & $0.42 \pm 0.11$ & 0.90 & -0.11 & 0.10 & 0.43 & 0.47 \\
\hline 2011 & NRDA & 2 & 9 & 21 & $0.89 \pm 0.11$ & $0.79 \pm 0.09$ & 0.89 & -0.12 & 0.11 & 0.22 & 0.18 \\
\hline 2011 & NRDA & 3 & 8 & 24 & $1.00 \pm 0.00$ & $0.83 \pm 0.08$ & 0.83 & -0.18 & 0.17 & 0.02 & 0.12 \\
\hline 2012 & Zengel & 1 & 5 & 13 & $1.00 \pm 0.00$ & $0.73 \pm 0.07$ & 0.73 & -0.31 & 0.27 & $<0.01$ & 0.02 \\
\hline 2013 & Zengel & 1 & 5 & 8 & $1.00 \pm 0.00$ & $0.35 \pm 0.13$ & 0.35 & -1.04 & 0.65 & $<0.01$ & $<0.01$ \\
\hline
\end{tabular}

Species composition expressed as the proportion (prpt.) of U. longisignalis (to U. longisignalis $+U$. spinicarpa). U. longisignalis is the typical dominant species. Data include response ratios (RR) (proportion U. longisignalis for oiled sites/proportion U. longisignalis for reference sites), proportional reduction with oiling (reduction), and significance tests for each combination of study-zone-by-year. Log response ratios (ln RR) less than zero indicate reduced $U$. longisignalis dominance (and increased relative abundance of $U$. spinicarpa) for oiled versus reference sites. Raw species composition data were arcsine square root transformed for $t$ tests, non-parametric Mann-Whitney U (MWU) tests also included

Overall, burrow densities at the reference sites were consistent with those expected for the region (Mouton and Felder 1996; Tong et al. 2013; McFarlin et al. 2015). Burrow densities at the oiled sites were reduced across multiple years. A similar effect was observed in heavily oiled areas following a prior spill of no. 2 fuel oil outside the Gulf region (Krebs and Burns 1977; Culbertson et al. 2007). We suspect that the relatively low densities of fiddler crabs at the marsh edge in our reference areas in 2010, compared to most of our reference values and literature sources, may have been due to low levels of oiling at some of these sites in 2010 that were no longer visible by the time of sampling. This interpretation is consistent with very light to light shoreline oiling recorded for two of these reference sites during Shoreline Cleanup Assessment Technique (SCAT) surveys (Michel et al. 2013; NOAA 2014). Low levels of oiling for at least a short time could explain why reference values in Zone 1 in 2010 were similar

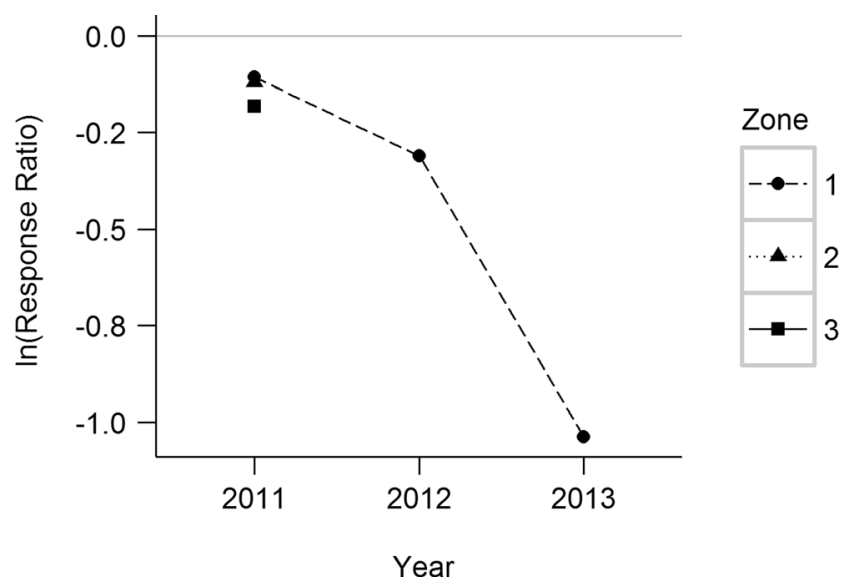

Fig. 4 Log response ratios (oiled : reference) for fiddler crab species composition by zone and year. Values less than zero indicate reduced $U$. longisignalis dominance (and increased relative abundance of $U$. spinicarpa) for oiled versus reference sites. Log response ratios were significantly lower than zero for the combined analysis across all studyzone-by-year observations ( $t$ test, $p=0.06$; Wilcoxon signed-rank test, $p=0.03$ ) to oiled values in Zone 3. Lower levels of non-persistent oiling possibly occurred at a number of other reference sites as well, due to widespread oiling across the study area. If so, light oiling at some reference sites would have made all of our comparisons between oiled and reference sites conservative.

Burrow Diameter The oil spill also reduced fiddler crab burrow diameters, but the effect had a shorter duration (up to 2 years) compared to effects on burrow density. As with oil effects on burrow density, effects on burrow size persisted longer at the seaward marsh edge, where oiling levels and vegetation impacts were greater. Early yet shorter-term reductions in burrow diameter in oiled areas, coupled with reductions in density, point to high fiddler crab mortality across all size classes shortly after the oil initially came ashore, due to smothering or toxicity caused by oiling. Subsequent recruitment would have led to initial populations dominated by younger (smaller) crabs in oiled areas compared to reference sites. Over time, crab size would recover through growth of recruited individuals or immigration of adult crabs from adjacent areas.

Species Composition Fiddler crab species composition was also altered by the oil spill. Both oiling and associated habitat changes may have led to this change. U. longisignalis typically dominates densely vegetated salt marsh sites in the region, whereas $U$. spinicarpa dominates sparsely vegetated areas with clay soils, such as along canal banks (Mouton and Felder 1995, 1996). Where the two species co-occur in salt marsh sites dominated by $U$. longisignalis, $U$. spinicarpa is typically restricted to the seaward marsh edge and typically comprises $\leq 10 \%$ of the population (Mouton and Felder 1996). Loss of vegetation cover coupled with residual oiling overlaid with thin algal mats and clay sediments may have led to reduced dominance of $U$. longisignalis and increased relative abundance of $U$. spinicarpa in heavily oiled sites (Zengel et al. 2014, 2015a). During sampling in 2012-2013, 
$U$. longisignalis was typically captured in vegetated areas, whereas $U$. spinicarpa was typically captured in unvegetated or sparsely vegetated areas with remaining surface oil (Zengel et al. 2014, 2015a). Our interpretation is greatly strengthened by results from experimental plantings of Spartina alterniflora at oiled sites: where marsh vegetation cover was restored, fiddler crab species composition returned to strong dominance by $U$. longisignalis (Zengel et al. 2014). Qualitatively, Deis et al. (2015) also observed strong dominance by $U$. longisignalis where Spartina alterniflora stem density recovered in their sites. These findings suggest that fiddler crab species composition will not recover at oiled sites until the vegetation recovers. Changes in fiddler crab species composition could have implications for marsh structure and function, but no studies of such differences are available. Nevertheless, if these two fiddler crab species differ in feeding activities, burrowing behavior, productivity, nutritive value, or interactions with other species, changes in species composition could have meaningful impact. At a minimum, $U$. spinicarpa is generally smaller than $U$. longisignalis and tends to have lower burrow densities and lower biomass (Mouton and Felder 1995, 1996), so it is likely that the two species are not ecologically equivalent in terms of supporting salt marsh function and services.

We conclude that the Deepwater Horizon oil spill had a substantial impact on salt marsh fiddler crabs, and that full recovery of crabs had not occurred as of 2014. There were possible signs of recovery as early as 2011 , possibly due to fiddler crab recruitment or immigration into areas where oil on the marsh surface had weathered and perhaps where shoreline cleanup treatments had also occurred in some cases (Zengel et al. 2015a). However, improvements were temporary for burrow density, which declined again through at least 2013 (along with species composition), perhaps due to residual oiling, oil remobilization during storms and erosion events, and continuing habitat alterations (Zengel et al. 2014, 2015a; see also Pennings et al. 2014 regarding "ecological traps"). Residual oiling in marsh soils, including polycyclic aromatic hydrocarbons (PAHs) (Turner et al. 2014; Zengel et al. 2015 b), could limit fiddler crab recovery, through effects on recruitment, burrowing activity, feeding, growth, and survival. Full recovery is also unlikely until the marsh vegetation recovers, and total fiddler crab recovery may lag vegetation recovery (Zengel et al. 2014). Full recovery could take as long as 2 to 4 years once oiling and habitat conditions are suitable to support normal fiddler crab life-history functions (2 to 4 years being the estimated time to re-establish the population age-size structure via new recruitment and growth, based on the oldest and largest individuals [Montague 1980; Mouton and Felder 1995; de M.M. Costa and Soares-Gomes 2015]). Where heavily oiled marshes have experienced accelerated erosion as a result of the spill, these habitat losses would represent additional losses of fiddler crabs. As erosional losses were not examined in our study, spill impacts on fiddler crabs may be even greater than described here. In turn, oil spill effects on fiddler crabs and their burrows may have influenced several other ecosystem processes and attributes, including marsh vegetation productivity, marsh soil characteristics, and important species that depend on fiddler crabs as prey.

Acknowledgments This paper relies on data collected as part of investigations being conducted cooperatively among NOAA, other Federal and State natural resource agencies, and BP as part of the Deepwater Horizon NRDA. The interpretations and conclusions presented in the paper are those of the authors and not necessarily of all participants in the cooperative studies upon which the paper is based. We thank NOAA, the State of Louisiana, the National Science Foundation, and the Gulf of Mexico Research Initiative for funding support. Data used in this paper are publically available at $\mathrm{https}$ ://dwhdiver.orr.noaa.gov/. GoMRI data are publicly available through the Gulf of Mexico Research Initiative Information and Data Cooperative (GRIIDC) at https://data. gulfresearchinitiative.org/ (doi:10.7266/N7FF3Q9S).

Open Access This article is distributed under the terms of the Creative Commons Attribution 4.0 International License (http:// creativecommons.org/licenses/by/4.0/), which permits unrestricted use, distribution, and reproduction in any medium, provided you give appropriate credit to the original author(s) and the source, provide a link to the Creative Commons license, and indicate if changes were made.

\section{References}

Bertness, M.D. 1985. Fiddler crab regulation of Spartina alterniflora production on a New England salt marsh. Ecology 66: 1042-1055.

Burger, J., J. Brzorad, and M. Gochfeld. 1991. Immediate effects of an oil spill on behavior of fiddler crabs (Uca pugnax). Archives of Environmental Contamination and Toxicology 20: 404-409.

Burger, J., J. Brzorad, and M. Gochfeld. 1992. Effects of an oil spill on emergence and mortality in fiddler crabs Uca pugnax. Environmental Monitoring and Assessment 22: 107-115.

Burns, K.A., and J.M. Teal. 1979. The West Falmouth oil spill: hydrocarbons in the salt marsh ecosystem. Estuarine and Coastal Marine Science 8: 349-360.

Culbertson, J.B., I. Valiela, E.E. Peacock, C.M. Reddy, A. Carter, and R. VanderKruik. 2007. Long-term biological effects of petroleum residues on fiddler crabs in salt marshes. Marine Pollution Bulletin 54: 955-962.

de M.M. Costa, T., and A. Soares-Gomes. 2015. Secondary production of the fiddler crab Uca rapax from mangrove areas under anthropogenic eutrophication in the Western Atlantic, Brazil. Marine Pollution Bulletin (in press), doi:10.1016/j.marpolbul.2015.10.061. Accessed 3 Jan 2016.

Deis, D.R., J.W. Fleeger, S.M. Bourgoin, I.A. Mendelssohn, Q. Lin, and A. Hou. 2015. Effects of shoreline oiling on salt marsh epifaunal macroinvertebrates. PeerJ PrePrints 3, e1849.

DePatra, K.D., and L.A. Levin. 1989. Evidence of the passive deposition of meiofauna into fiddler crab burrows. Journal of Experimental Marine Biology and Ecology 125: 173-192.

Fleeger, J.W., K.R. Carman, M.R. Riggio, I.A. Mendelssohn, Q. Lin, A. Hou, D.R. Deis, and S. Zengel. 2015. Recovery of saltmarsh benthic microalgae and meiofauna from the Deepwater Horizon oil spill linked to recovery of Spartina alterniflora. Marine Ecology Progress Series 536: 39-54.

Fodrie, F.J., K.W. Able, F. Galvez, K.L. Heck, O.P. Jensen, P.C. LópezDuarte, C.W. Martin, R.E. Turner, and A. Whitehead. 2014. 
Integrating organismal and population responses of estuarine fishes in Macondo spill research. BioScience 64: 778-788.

Gittman, R.K., and D.A. Keller. 2013. Fiddler crabs facilitate Spartina alterniflora growth, mitigating periwinkle overgrazing of marsh habitat. Ecology 94: 2709-2718.

Gribsholt, B., J.E. Kostka, and E. Kristensen. 2003. Impact of fiddler crabs and plant roots on sediment biogeochemistry in a Georgia saltmarsh. Marine Ecology Progress Series 259: 237-251.

Grimes, B.H., M.T. Huish, J.H. Kerby, and D. Moran. 1989. Species profiles: life histories and environmental requirements of coastal fishes and invertebrates (mid-Atlantic), Atlantic marsh fiddler. U.S. Fish and Wildlife Service Biological Report 82 (11.114). Available at http://www.nwrc.usgs.gov/wdb/pub/species_profiles/ 82_11-114.pdf. Accessed 6 Jan 2016.

Harmon, D.M., and H.J. Stains. 1979. The raccoon (Procyon lotor) on St. Catherines Island, Georgia. 5. Winter, spring, and summer food habits. American Museum Novitates 2679: 1-24.

Heard, R.W. 1982. Observations on the food and food habits of clapper rails (Rallus longirostris Boddaert) from tidal marshes along the East and Gulf Coasts of the United States. Gulf Research Reports 7: $125-135$

Hedges, L.V., J. Gurevitch, and P.S. Curtis. 1999. The meta-analysis of response ratios in experimental ecology. Ecology 80: 1150-1156.

Hoffman, J.A., J. Katz, and M.D. Bertness. 1984. Fiddler crab depositfeeding and meiofaunal abundance in salt marsh habitats. Journal of Experimental Marine Biology and Ecology 82: 161-174.

Holdredge, C., M.D. Bertness, N.C. Herrmann, and K.B. Gedan. 2010. Fiddler crab control of cordgrass primary production in sandy sediments. Marine Ecology Progress Series 399: 253-259.

Katz, L.C. 1980. Effects of burrowing by the fiddler crab Uca pugnax (Smith). Estuarine and Coastal Marine Science 11: 233-237.

Kokaly, R.F., B.R. Couvillion, J.M. Holloway, D.A. Roberts, S.L. Ustin, S.H. Peterson, S. Khanna, and S.C. Piazza. 2013. Spectroscopic remote sensing of the distribution and persistence of oil from the Deepwater Horizon spill in Barataria Bay marshes. Remote Sensing of Environment 129: 210-230.

Krebs, C.T., and K.A. Burns. 1977. Long-term effects of an oil spill on populations of the salt-marsh crab Uca pugnax. Science 197: 484 487.

Lin, Q., and I.A. Mendelssohn. 2012. Impacts and recovery of the Deepwater Horizon oil spill on vegetation structure and function of coastal salt marshes in the northern Gulf of Mexico. Environmental Science \& Technology 46: 3737-3743.

Mapstone, B.D. 1995. Scalable decision rules for environmental impact studies: effect size, type I, and type II errors. Ecological Applications 5: 401-410.

McCall, B.D., and S.C. Pennings. 2012. Disturbance and recovery of salt marsh arthropod communities following BP Deepwater Horizon oil spill. PLoS One 7, e32735.

McClenachan, G., R.E. Turner, and A.W. Tweel. 2013. Effects of oil on the rate and trajectory of Louisiana marsh shoreline erosion. Environmental Research Letters 8: 044030.

McFarlin, C.R., T.D. Bishop, M.W. Hester, and M. Alber. 2015. Contextdependent effects of the loss of Spartina alterniflora on salt marsh invertebrate communities. Estuarine, Coastal and Shelf Science 163: 218-230.

Melville, F., L.E. Andersen, and D.F. Jolley. 2009. The Gladstone (Australia) oil spill - impacts on intertidal areas: baseline and six months post-spill. Marine Pollution Bulletin 58: 263-271.

Michel, J., and N. Rutherford. 2014. Impacts, recovery rates, and treatment options for spilled oil in marshes. Marine Pollution Bulletin 82: $19-25$.

Michel, J., C.L. Montague, C.E. Proffitt, and S. Zengel. 2012. Work plan for MC252 oil impacts to fiddler crabs and periwinkles along the Gulf of Mexico. National Oceanic and Atmospheric Administration
(NOAA) report. Available at http://www.gulfspillrestoration.noaa. gov/oil-spill/gulf-spill-data/. Accessed 6 Nov 2015.

Michel, J., E.H. Owens, S. Zengel, A. Graham, Z. Nixon, T. Allard, W. Holton, P.D. Reimer, A. Lamarche, M. White, N. Rutherford, C. Childs, G. Mauseth, G. Challenger, and E. Taylor. 2013. Extent and degree of shoreline oiling: Deepwater Horizon oil spill, Gulf of Mexico, USA. PLoS One 8, e65087.

Montague, C.L. 1980. A natural history of temperate Western Atlantic fiddler crabs (genus $U c a$ ) with reference to their impact on the salt marsh. Contributions in Marine Science 23: 25-55.

Montague, C.L. 1982. The influence of fiddler crab burrows and burrowing on metabolic processes in salt marsh sediments. In Estuarine comparisons, ed. V.S. Kennedy, 283-301. New York: Academic.

Mouton, E.C., and D.L. Felder. 1995. Reproduction of the fiddler crabs Uca longisignalis and Uca spinicarpa in a Gulf of Mexico salt marsh. Estuaries 18: 469-481.

Mouton, E.C., and D.L. Felder. 1996. Burrow distributions and population estimates for the fiddler crabs Uca spinicarpa and Uca longisignalis in a Gulf of Mexico salt marsh. Estuaries 19: 51-61.

NOAA. 2014. Shoreline oiling assessment technique (SCAT) maximum oiling observed, map and GIS layer (30 September 2014). Environmental Response Management Application (ERMA), Deepwater Gulf Response. Available at http://gomex.erma.noaa. gov/. Accessed 6 Nov 2015.

Pennings, S.C., B.D. McCall, and L. Hooper-Bui. 2014. Effects of oil spills on terrestrial arthropods in coastal wetlands. BioScience 64: 789-795.

Peterson, G.W., and R.E. Turner. 1994. The value of salt marsh edge vs interior as a habitat for fish and decapod crustaceans in a Louisiana tidal marsh. Estuaries 17: 235-262.

Rützler, K., and W. Sterrer. 1970. Oil pollution: damage observed in tropical communities along the Atlantic seaboard of Panama. BioScience 20: 222-224.

Silliman, B.R., J. Van de Koppel, M.W. McCoy, G.N. Kasozi, K. Earl, P.N. Adams, and A.R. Zimmerman. 2012. Degradation and resilience in Louisiana salt marshes after the BP-Deepwater Horizon oil spill. Proceedings of the National Academy of Sciences USA 109: 11234-11239.

Smith, S.M., and M.C. Tyrrell. 2012. Effects of mud fiddler crabs (Uca pugnax) on the recruitment of halophyte seedlings in salt marsh dieback areas of Cape Cod (Massachusetts, USA). Ecological Research 27: 233-237.

Taylor, D.I., and B.R. Allanson. 1993. Impact of dense crab populations on carbon exchanges across the surface of a saltmarsh. Marine Ecology Progress Series 101: 119-129.

Teal, J.M. 1962. Energy flow in the salt marsh ecosystem of Georgia Ecology 43: 614-624.

Teal, J.M., and R.W. Howarth. 1984. Oil spill studies: a review of ecological effects. Environmental Management 8: 27-44.

Teal, J.M., J.W. Farrington, K.A. Burns, J.J. Stegeman, B.W. Tripp, B. Woodin, and C. Phinney. 1992. The West Falmouth oil spill after 20 years: fate of fuel oil compounds and effects on animals. Marine Pollution Bulletin 24: 607-614.

Thomas, C.R., and L.K. Blum. 2010. Importance of the fiddler crab Uca pugnax to salt marsh soil organic matter accumulation. Marine Ecology Progress Series 414: 167-177.

Tong, C., J.J. Baustian, S.A. Graham, and I.A. Mendelssohn. 2013. Salt marsh restoration with sediment-slurry application: effects on benthic macroinvertebrates and associated soil-plant variables. Ecological Engineering 51: 151-160.

Tucker, A.D., N.N. FitzSimmons, and J.W. Gibbons. 1995. Resource partitioning by the estuarine turtle Malaclemys terrapin: trophic, spatial, and temporal foraging constraints. Herpetologica 51: $167-$ 181. 
Turner, R.E., E.B. Overton, B.M. Meyer, S.M. Miles, G. McClenachan, L. Hooper-Bui, A.S. Engel, E.M. Swenson, J.M. Lee, C.S. Milan, and H. Gao. 2014. Distribution and recovery trajectory of Macondo (Mississippi Canyon 252) oil in Louisiana coastal wetlands. Marine Pollution Bulletin 87: 57-67.

U.S. District Court. 2015. Oil spill by the oil rig "Deepwater Horizon" in the Gulf of Mexico, on April 20, 2010, findings of fact and conclusions of law: phase two trial. United States District Court for the Eastern District of Louisiana. Available at http://www.laed.uscourts. gov/sites/default/files/OilSpill/Orders/1152015FindingsPhaseTwo. pdf. Accessed 6 Jan 2016.

Zengel, S., N. Rutherford, B.M. Bernik, Z. Nixon, and J. Michel. 2014. Salt marsh remediation and the Deepwater Horizon oil spill, the role of planting in vegetation and macroinvertebrate recovery. International Oil Spill Conference Proceedings 2014: 1985-1999.

Zengel, S., B.M. Bernik, N. Rutherford, Z. Nixon, and J. Michel. 2015a. Heavily oiled salt marsh following the Deepwater Horizon oil spill, ecological comparisons of shoreline cleanup treatments and recovery. PLoS One 10, e0132324.

Zengel, S., C.L. Montague, S.C. Pennings, S.P. Powers, M. Steinhoff, G. French Fricano, C. Schlemme, M. Zhang, J. Oehrig, Z. Nixon, S. Rouhani, and J. Michel. 2015b. Impacts of the Deepwater Horizon oil spill on salt marsh periwinkles (Littoraria irrorata). Environmental Science \& Technology, doi:10.1021/acs.est. 5b04371. Accessed 6 Jan 2016. 